\title{
Moderate Stress Enhances Immediate and Delayed Retrieval of Educationally Relevant Material in Healthy Young Men
}

\author{
Almut Hupbach and Rachel Fieman \\ Lehigh University
}

\begin{abstract}
Retrieval practice is a powerful memory enhancer. However, in educational settings, test taking is often experienced as a stressful event. While it is known that stress can impair retrieval processes, little is known about the delayed consequences of testing memory for educationally relevant material under stressful conditions, which is the focus of the present study. Participants ( 38 women, 37 men) memorized a scientific text passage on Day 1. On Day 2, they were either exposed to a stressor (cold pressor test; CPS) or a warm water control, and immediately afterward, they were asked to recall the text passage (i.e., retrieval under stress vs. control). Salivary cortisol was measured as an index of the stress response before, and $20 \mathrm{~min}$ after the CPS versus control treatment. The delayed effects of testing under stress were assessed with a final recall test on Day 3. In comparison to the control condition, CPS caused significant increases in salivary cortisol, and, surprisingly resulted in enhanced memory in men. Importantly, this enhancement was not only observed in the test that immediately followed the stressor, but also in the delayed test. In women, CPS caused only marginal increases in cortisol concentrations, and retrieval remained unaffected. Our study suggests that moderate stress can improve memory performance for educationally relevant material in a long-lasting manner in healthy young men.
\end{abstract}

Keywords: memory retrieval, stress, cold pressor, testing effect

Retrieving information from long-term memory is known to be a powerful memory enhancer (i.e., testing effect). Specifically, correct retrieval increases the probability of future successful remembering to a greater extent than restudying the same factual information (Karpicke, 2012; Roediger \& Karpicke, 2006). Therefore, it has been suggested that memory tests should be routinely incorporated into the learning process (McDaniel, Roediger, \& McDermott, 2007). These recommendations come from studies carried out under nonstressful conditions, both in the laboratory (e.g., Chan, McDermott, \& Roediger, 2006; Wheeler, Ewers, \& Buonanno, 2003) and in educational settings (e.g., McDaniel, Anderson, Derbish, \& Morrisette, 2007). However, "real" testing situations are often stressful; for example, many students experience anxiety and stress during test taking. Thus, stress might present a critical boundary condition for the reported benefits of testing on long-term retrieval. The present study tested this by assessing how stress affects the retrieval of educationally relevant material that was learned a day prior, under nonstressful conditions. We were interested in both the immediate and the delayed effects of stress; that is, memory performance was tested immediately after the stressor as well as after a delay when the stressor was no longer present.

This article was published Online First October 15, 2012.

Almut Hupbach and Rachel Fieman, Department of Psychology, Lehigh University.

The authors thank Nancy Duchesneau and Victoria Shiebler for their assistance with data collection.

Correspondence concerning this article should be addressed to Almut Hupbach, Department of Psychology, Lehigh University, 17 Memorial Drive East, Bethlehem, PA 18015. E-mail: hupbach@lehigh.edu
The experience of a stressor triggers a set of time-dependant endocrine, nervous, and immune systems responses (see, for example, review by Charmandari, Tsigos, \& Chrousos, 2005) that are associated with preparing an organism for a flight/fight response and survival (Cannon, 1929). Stress activates the sympathetic nervous system and causes the release of noradrenaline and adrenaline. Noradrenaline in turn stimulates the hypothalamic-pituitaryadrenal axis (HPA), eliciting a cascade of events, leading to the release of corticosteroids such as cortisol from the adrenal gland into the bloodstream (e.g., see review by Lupien \& McEwen, 1997). Importantly, cortisol can easily cross the blood-brain barrier and affects various brain systems through the activation of two types of corticosteroid receptors, Type-I (mineralcorticoid, MR) and Type-II receptors (glucocorticoids, GR; e.g., Lupien \& McEwen, 1997; Reul \& De Kloet, 1985). MR receptors have a high affinity for cortisol while GR receptors have a low affinity. Thus, under resting conditions, cortisol occupies mainly MR receptors. At times of acute stress, MR receptors become saturated and glucocorticoids also activate Type II receptors. While GRs are widely distributed throughout the brain, the highest expressions of MRs are found in the amygdala and the hippocampus, two systems critically involved in (emotional) memory processes. The effects of cortisol on memory function critically depend on the amount of freely circulating cortisol and in turn, differential involvement of MR and GR activation (De Kloet, Oitzl, \& Joels, 1999; Lupien \& McEwen, 1997; see also Discussion). While most cortisol effects are genomic and therefore delayed and long lasting, there are also rapid nongenomic effects that are mediated by membrane-bound receptors (e.g., Groeneweg, Karst, deKloet, \& Joels, 2011; Schwabe, Joëls, Roozendaal, Woolf, \& Oitzl, 2012).

Over the past 15 years, the impact of stress on memory has been extensively researched, first mainly in animal models, but later 
also in humans (see reviews by, for example, Lupien \& McEwen, 1997; Roozendaal, 2002; Schwabe et al., 2012; Wolf, 2009). The specific effects of stress on human memory depend on (a) the specific memory process in question (encoding, consolidation, retrieval; see, for example, Roozendaal, 2002), (b) the memory test (declarative vs. nondeclarative tests with only the former affected by stress; e.g., Kirschbaum, Wolf, May, Wippich, \& Hellhammer, 1996), (c) the nature of the to-be-remembered material (emotional vs. neutral, e.g., Smeets, Otgaar, Candel, \& Wolf, 2008), and (d) basal cortisol levels, which depend on the time of day, and the amount of cortisol increase attributable to the stressor or cortisone intake (e.g., Maheu, Collicutt, Kornik, Moszkowski, \& Lupien, 2005). Because of the variety of variables modulating the effect of stress on memory, results are generally mixed, that is, sometimes stress enhances memory, and sometimes it impairs or does not affect memory at all.

Specifically relevant for the present study are previous studies looking at the effects of stress/cortisol on memory retrieval. Most of the earlier studies administered cortisone orally. A metaanalysis of these studies by Het, Ramlow, and Wolf (2005) revealed consistent detrimental effects of cortisol on retrieval for neutral material, with an average medium effect size $(d=-.49)$. Studies using procedures such as the Trier Social Stress Test (TSST) or the Cold Pressor Test (CPS) that induce an endogenous stress response (and commonly result in a more moderate increase in cortisol) suggest an interaction of stress with the emotionality of the memory. Stress-induced elevation of cortisol does not affect neutral memories (e.g., Wolf, Schommer, Hellhammer, Reischies, \& Kirschbaum, 2002; Domes, Heinrichs, Rimmele, Reichwald, \& Hautzinger, 2004; but see Tollenaar, Elzinga, Spinhoven, \& Everaerd, 2008a), while it impairs retrieval of emotional material (Buchanan \& Tranel, 2008; Domes et al., 2004; Kuhlmann, Piel, \& Wolf, 2005; Smeets et al., 2008; but see Schwabe et al., 2009).

Another factor that seems to moderate the cortisol effects on retrieval is the concurrent activity of the noradrenergic system. Specifically, cortisol-related retrieval impairments are dependent on the noradrenergic activation of the basolateral amygdala (e.g., Roozendaal, Hahn, Nathan, deq Uervain, \& McGaugh, 2004; Roozendaal \& McGaugh, 2011). Noradrenergic activity in response to a psychological and physiological stressor is short-lived, while cortisol has both immediate nongenomic and delayed genomic effects (e.g., Schwabe et al., 2012). Most studies insert a time delay between the stressor and the memory test. This might further explain the lack of endogenous stress effects on memory for neutral material (Domes et al., 2004; Wolf et al., 2002): the noradrenergic effects necessary for the cortisol-induced alterations have already ceased at the time of test. At the same time, effects are still found for emotionally arousing material, because the material itself can reactivate the noradrenergic system (e.g., Segal \& Cahill, 2009). In fact, Tollenaar et al. (2008a) found significant relations between cortisol increase and retrieval impairment for negative and neutral word pairs when testing took place immediately after a psychological stressor, but not when retrieval was tested about $20 \mathrm{~min}$ after the stressor.

In line with Tollenaar et al. (2008a), and to mimic educational testing situations that are by many experienced as stressful, we tested memory immediately after a stress exposure. In extension to Tollenaar et al., we decided to use educationally relevant material (a coherent scientific text passage) instead of self-generated word pairs. Likely, educationally relevant material is more interesting and engaging for students, and this might modulate stress effects on memory. We are aware of only one study that used similarly interrelated material. Merz, Wolf, and Hennig (2010) showed impairing effects of psychological stress on the retrieval of biographical information. Because encoding, stress and retrieval took place within a single session, it is difficult to disentangle the effects of stress on retrieval from the effects of stress on consolidation. Based on Tollenaar et al. we expected impaired retrieval in the test that immediately followed the stressor. However, because of the rather scant literature on stress and retrieval of neutral content, and because of the study material used, we chose the conservative approach of nondirectional (two-tailed) hypothesis testing.

Beyond the immediate effects of stress on retrieval, does stress have prolonged consequences for memory? Answering this question is the second aim of the present study. We are aware of only three previous studies that assessed the long-term effects of retrieval under stress. Taverniers, Taylor, and Smeets (2012) assessed the effects of a prisoner-of-war exercise on retrieval of Rey-Osterrieth complex figures (ROCF) in Special Force candidates, and found that stress impaired both immediate and delayed recall. Importantly, the impairments were mediated by increases in cortisol concentrations, and not by subjective stress ratings. However, participants received the stress treatment before they encoded the figures, and thus, it is not entirely clear whether stress affected encoding and/or retrieval.

Tollenaar, Elzinga, Spinhoven, and Everaerd (2009) found that retrieval of emotional and neutral words was impaired by oral intake of hydrocortisone that took place $75 \mathrm{~min}$ before the test, and that this impairment remained (but did not further progress) when memory was tested again 2 weeks later. Especially relevant for the current study is another study by Tollenaar, Elzinga, Spinhoven, and Everaerd (2008b) that used a psychological stressor and found long-lasting effects of retrieval under stress, at least under some conditions. Participants studied negative and neutral word pairs and were tested with cued recall either 1 day or 5 weeks after encoding, under TSST or control conditions. Performance was at ceiling in the 1 day-delay group, but stress impaired recall of negative word associates when tested 5 weeks after encoding. When memory was again assessed 6 months later, the 5-week stress group recalled significantly less word pairs than a no-stress control group. In contrast, the 1-day stress group recalled marginally more than its respective control. In addition, the 5-week stress group's performance was worse at 6 months than their performance had been at 5 weeks, suggesting that stress did not only affect the reactivation of the memory but further impacted postreactivation reconsolidation processes.

That stress can affect human memory reconsolidation was also shown in two recent studies. Schwabe and Wolf (2010) found impairing effects of a socially evaluated CPS on 1-week delayed recall of neutral but not emotional autobiographical events that participants had retrieved prior to the stress treatment. In contrast, Coccoz, Maldonado, and Delorenzi (2011) found that CPS enhanced declarative memory for neutral content (pairs of syllables). In contrast to Tollenaar et al. (2008b) and Schwabe and Wolf (2010) who asked participants to consciously retrieve the memory before the stressor, $\mathrm{Coccoz}$ et al. repeated parts of the original learning procedure as a reminder before the stressor. Despite the 
difference in reactivation, material and time delays, it remains unclear what caused the differential findings in these studies. Hence, it is difficult to predict the direction of delayed effects of testing under stress.

\section{Current Study}

Three previous studies have reported long-lasting memory impairments when retrieval took place after cortisol-increasing procedures (Taverniers et al., 2012; Tollenaar et al., 2008b, 2009). Taverniers et al. used the ROCF test and Tollenaar et al. used individual words or word pairs as material. In educational settings, however, the to-be-remembered material is usually thematically related and interconnected. To make our study as educationally relevant as possible, we used a neutral text passage of scientific content that has been used in studies on the testing effect (Roediger \& Karpicke, 2006) and that originates from a test-preparation book for the Test of English as a Foreign Language (TOEFL; Rogers, 2001). The text passage was studied and recalled on a first day. On a second day, we subjected participants to cold pressor stress (CPS) or a warm water control. We chose a physiological instead of psychological stressor because we were interested in assessing the effects of stress on memory retrieval without the potential confounding psychological effects that can arise from the commonly used psychological stress procedures (e.g., TSST), such as prolonged ruminations or feelings of embarrassment, which by themselves could negatively affect retrieval (see Discussion). To induce CPS, participants were asked to submerge their arm in ice-cold water, which causes a painful stimulation. This increases the activity of the noradrenergic system and the HPA axis, which in turn causes cortisol levels to rise (Lovallo, 1975; but see Smeets et al., 2012 for failures of CPS to trigger HPA responses). To mimic testing situations in educational settings, in which students attempt to retrieve information while they are anxious or stressed, we tested memory immediately after CPS when the painful sensation was still acute. To assess how testing under stress affects future retrieval at a time when the stressor is no longer present, we tested memory again 24 hrs later on a third day. Based on Tollenaar et al. (2008a), we expected CPS to impair memory retrieval immediately after the stressor. However, as stated above, because of the specifics of our design and material, we remained open to the possibility of other than impairing effects and chose two-tailed tests for our statistical analyses. For the final recall that took place $24 \mathrm{hr}$ after the stressor, three possibilities exist. If the amount of recall on Day 2 determines what can be retrieved on Day 3, (i.e., how much information is reencoded or rehearsed, cf., Tollenaar et al., 2008b, 2009), then we would expect long-lasting memory impairments in the stress in comparison to the control group. If, however, stress affects only the retrieval process, while not affecting the integrity of the memory trace (cf., Roozendaal, 2002), then we would expect impairment on Day 2, but no difference between the CPS and the warm water control on Day 3 . Another possibility is that stress affects not only the retrieval, but in addition the postretrieval restabilization (i.e., reconsolidation) of the memory (cf. Tollenaar et al., 2008b). As outlined above, previous research has found both enhancing and impairing effects of stress on reconsolidation, making it difficult to predict a specific direction of influence.
Method

\section{Participants}

The final sample consisted of 75 healthy subjects ( 38 women and $37 \mathrm{men}) .{ }^{1}$ All participants were nonsmokers, free of psychiatric and neurological disorders, and were not taking any corticosteroid-based medications. Participants were randomly assigned to the warm water control (19 women, 19 men) or the stress group (19 women, 18 men). Before the start of the experiment, all participants provided written informed consent. Participants received either course credits or monetary compensation for participation in the experiment (type of compensation was equally distributed across the experimental conditions).

\section{Memory Test}

The to-be memorized material consisted of a prose passage that has been used in studies on the testing effect (Roediger \& Karpicke, 2006). The scientific text passage is called "The Sun" and is part of the reading comprehension section of a testpreparation book for the Test of English as a Foreign Language (TOEFL; Rogers, 2001). Following Roediger \& Karpicke, the passage was divided into 30 idea units for scoring purposes. The passage was 256 words in length.

\section{Stress Manipulation}

Stress was induced by exposing participants to cold pressor stress. Participants submerged their nondominant arm, including the elbow, into a bucket filled with ice water $\left(0-2{ }^{\circ} \mathrm{C}\right)$. In the control condition, participants submerged their arm in warm water $\left(35-37^{\circ} \mathrm{C}\right)$. Participants were asked to keep their arm in the water for $2 \mathrm{~min}$, but were explicitly told that they could remove their arm from the water bath if the pain became too uncomfortable. The experimenter closely watched the participants, and recorded the exact time of submersion. Although many studies use 3-min submersion times, shorter versions have proved to be equally effective in elevating cortisol concentrations and affecting psychological processes (e.g., Duncko, Johnson, Merikangas, \& Grillon, 2009; Porcelli \& Delgado, 2009).

\section{Salivary Sampling and Biochemical Analysis}

Salivary cortisol was measured to objectively assess whether the CPS caused a physiological stress response. Saliva was collected using a cotton oral swab (Salimetrics) which participants placed

\footnotetext{
${ }^{1}$ Originally, 95 participants between the ages of 18 and 35 were recruited through advertisements at Lehigh University. Twenty participants were excluded from the final data set for various reasons related to cortisol measurements or memory performance. Cortisol: for two men and three women, no cortisol could be detected in their saliva samples, three men and two women had baseline cortisol levels that were three $S D$ s above the mean of the entire sample, and one woman in the warm water condition had a cortisol increase that was more than $3 S D$ s above her respective group mean. Memory performance: two men and three women stated that they had practiced memorizing the text passage outside of the experimental sessions, and for two men and two women memory performance on Day 1 (baseline) was at or below the pre-experimentally defined cut-off for low performance (12 idea units, i.e., $\leq 40 \%$ ).
} 
under their tongue for $2 \mathrm{~min}$, before it was placed into a storage tube. Participants were instructed to abstain from eating, physical exercise, soft drinks, and caffeine for at least one hour prior to saliva sampling. The first sample (baseline) was taken upon arrival and a brief resting period on the second day of the experiment. The second sample was taken $20 \mathrm{~min}$ after the CPS or control condition. We chose a 20-min delay because previous studies have shown that salivary cortisol peaks at 20-30 min after the onset of CPS (e.g., Schoof, Wolf, \& Smeets, 2009; Schwabe, Haddad, \& Schachinger, 2008). Samples were stored at $-20{ }^{\circ} \mathrm{C}$ immediately after collection and until analysis. The samples were analyzed by an independent commercial testing site, Salimetrics. Salivary cortisol concentrations were analyzed using immunoassays. Each sample was analyzed twice (intraassay variability $<4 \%$ ), and the average of the two levels for each sample was used as a dependent measure in statistical analyses.

\section{Stress and Pain Rating}

Two independent scales were used to assess the level of pain and the level of stress participants experienced during the water bath. The scale ranged from 0 ("not stressful/painful at all") to 10 ("extremely stressful/painful").

\section{Experimental Procedure}

Testing took place midday through afternoon (11 a.m.-4:30 p.m.) to avoid times of naturally occurring high (morning) and low (evening) cortisol levels. Participants were tested during three sessions. On Day 1, small groups of participants ( 8 or fewer) were asked to read and memorize the text passage for a later memory test. After a study period of $7 \mathrm{~min}$, participants engaged in a 2-min filler task (number puzzle). Then, they were asked to recall and write down the facts they learned from the text passage.

On Day 2 (24 hr after Day 1 testing), participants were seen individually and underwent either the CPS or a warm water control procedure (see above). Immediately after the CPS or warm water treatment, participants were asked to recall the passage in the same way as outlined for Day 1. In addition, participants were asked to indicate the level of pain and the level of stress they had experienced during the water bath. A second saliva sample was taken 20 min after the onset of the CPS versus control treatment.

On Day 3 (24 hr after Day 2 testing), a final recall of the text passage was assessed in small groups. As in the previous sessions, participants were asked to write down as many facts as they could remember from the text passage. A questionnaire subsequent to the recall asked participants to indicate whether they had practiced recalling the passage outside of the experimental sessions, and if yes, what method for practice they had used. Women were also asked whether they were taking hormonal birth control medications. Fifteen women ( 8 in the CPS and 7 in the warm water group) indicated that they were using hormonal birth control medications, and 2 women (1 in each group) did not answer the question.

\section{Results}

\section{Subjective and Physiological Stress Responses}

Subjective stress ratings. As a manipulation check, we analyzed whether the CPS and the warm water control produced different stress and pain ratings. Stress and pain ratings were analyzed with 2 (Gender) $\times 2$ (Condition: CPS vs. control) between-subjects analyses of variance (ANOVAs). For the stress ratings, the analysis revealed significant effects of Gender, $F(1$, $71)=5.40, M S E=3.19, p=.023$, and Condition, $F(1,71)=$ 109.93, $M S E=3.19, p<.001$, but no significant interaction $(F<$ $1)$. Women $(M=3.16, S D=2.77)$ had overall lower stress ratings than men $(M=4.05, S D=2.87)$, and the CPS $(M=5.78, S D=$ 2.38) led to significantly higher stress ratings than the warm water control $(M=1.47, S D=1.06)$. For the pain ratings, the analysis only resulted in a significant effect of Condition, $F(1,71)=$ 294.73, $M S E=2.11, p<.001$; all other effects: $F<1$ : pain was rated significantly higher after the CPS $(M=6.86, S D=2.02)$ than the warm water control $(M=1.11, S D=.311)$.

Cortisol responses. Mean salivary cortisol levels before and after the CPS versus warm water control treatment are displayed in Figure 1.

A mixed factorial ANOVA was used to analyze baseline and delayed cortisol responses with Gender and Condition (CPS vs. control) as between-subjects factors, and Time of Sampling (before vs. after the treatment) as a within-subject factor. This analysis resulted in a marginally significant three-way interaction, $F(1$, $71)=3.06, M S E=5.25, p=.085$. This three-way interaction was further analyzed by (a) comparing the before and after treatment cortisol levels in the CPS groups, and (b) comparing the four experimental groups' cortisol levels after the treatment.

(a) A (Gender) $\times 2$ (Time of Sampling: before vs. after the treatment) mixed factorial ANOVA of cortisol concentrations in the cold water condition revealed a significant interaction, $F(1,35)=8.23, M S E=8.76, p=.007$. Analyses of the simple effects showed that men showed significantly higher levels of cortisol after the CPS in comparison to baseline, $F(1,35)=33.28$, $M S E=8.76, p<.001$. This difference was only marginally significant in women, $F(1,35)=3.29, M S E=8.76, p=.078$.

(b) A (Gender) $\times 2$ (Condition: CPS vs. control) betweensubjects ANOVA for the cortisol levels obtained 20 min after the treatment showed a significant interaction between Gender and Condition, $F(1,71)=5.26, M S E=16.25, p=.025$. Analyses of the simple effects showed that men's and women's cortisol levels

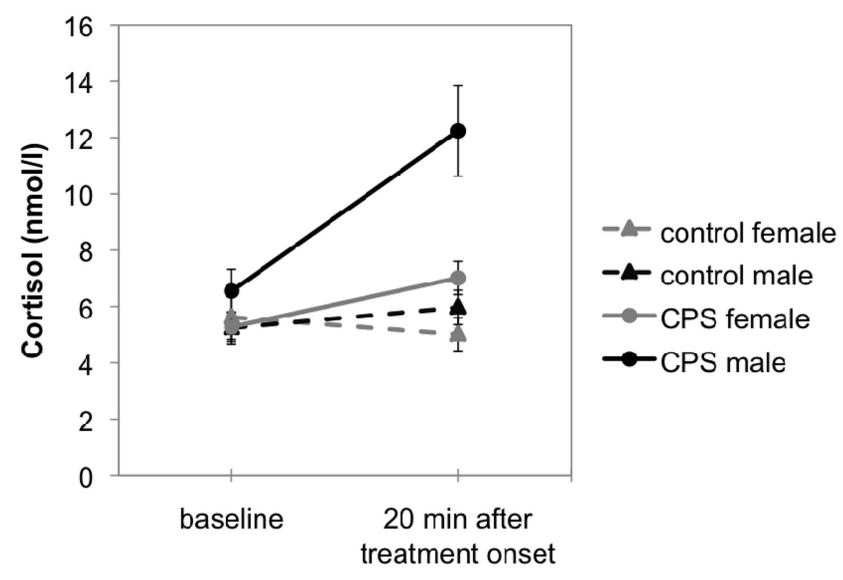

Figure 1. Mean salivary cortisol levels in men and women before and after the cold pressor versus warm water control treatment. Error bars represent SEMs. 
did not differ in the warm water condition $(F<1)$, but that men showed significantly higher levels of cortisol than women in the cold pressor condition, $F(1,72)=11.80, M S E=20.48, p=.001$. In addition, the CPS resulted in significantly higher cortisol levels than the warm water control for men, $F(1,72)=19.15, M S E=$ 18.51, $p<.001$, but not for women, $F(1,72)=2.06, M S E=$ $18.51, p=.155$. (There were no significant differences in baseline cortisol concentrations, $F \leq 1.52, p \geq .22$.)

\section{Memory Performance}

Scoring. Recall performance on all days was graded by giving 1 point for each correctly recalled idea unit (out of 30). Two independent raters graded each recall test. Interrater reliability was .98 , all discrepancies were discussed and resolved.

Memory performance on Day 1 (baseline). A 2 (Gender) $\times$ 2 (Condition: CPS vs. control) between-subjects ANOVA on the number of idea units recalled on Day 1 revealed a marginally significant effect of Gender, $F(1,71)=3.32, M S E=10.63, p=$ .073 , showing that men $(M=18.90, S D=3.02)$ recalled more idea units than women $(M=17.54, S D=3.48)$.

Memory performance on Day 2 and 3. Mean recall performances are depicted in Figure 2.

Because of differential effect of the CPS on women and men, and the marginally significant difference in Day 1 memory performance between women and men, we analyzed recall performance for Day 2 and 3 for men and women separately. (The identical pattern of results, that is, a significant interaction between Gender and Condition, $F(1,71)=6.35, M S E=26.88, p=.014$, emerges when men and women are analyzed in a combined analysis). For women, a 2 (Condition: CPS vs. control) $\times 2$ (Test Day: Day 2 vs. Day 3) mixed factorial ANOVA on the number of idea units recalled, with memory performance on Day 1 as a covariate revealed only a significant effect of the covariate, $F(1,35)=$ 95.66, $M S E=7.30, p<.001$, but no significant effects of Test Day, Condition, or their interaction $\left(F_{\mathrm{S}}<1\right)$, which is not surprising given the blunted cortisol responses in women. For men, the same analysis showed also a significant effect of the covariate, $F(1,34)=46.35, M S E=11.88, p<.001$, and importantly, a significant effect of Condition, $F(1,34)=6.08, M S E=11.88$,

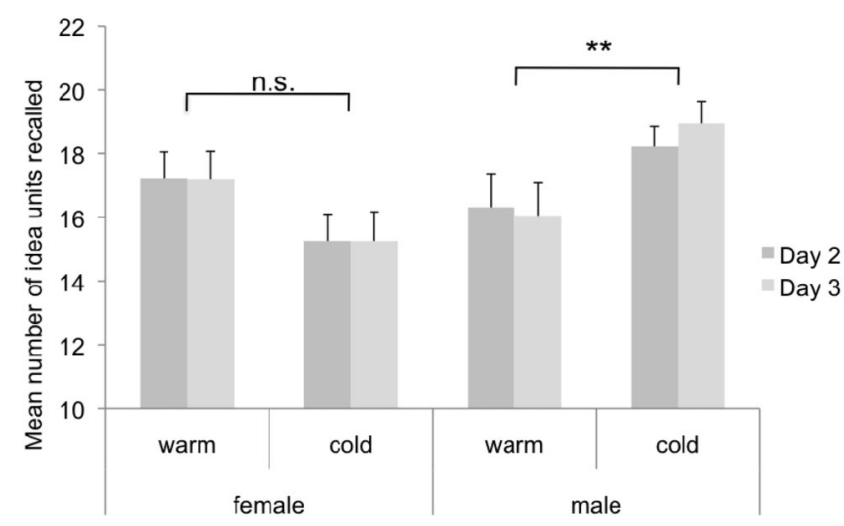

Figure 2. Mean number of idea units recalled on Day 2 and Day 3 by women and men after the cold pressor versus warm water control treatment. Error bars represent SEMs. $p=.019$, but no effect of Test Day, and no interaction between the two factors $(F \mathrm{~s} \leq 2.08, p \geq .16)$.

In addition, to better account for differences in baseline performance, we analyzed the proportional amount of forgetting that occurred between Day 1 and Day 2 by using the following formula: forgetting Day $2=$ (number of idea units recalled on Day 1 - number of idea units recalled on Day 2)/number of idea units recalled on Day 1. An analogue score was calculated for the proportion of forgetting between Day 1 and Day 3. For women, a 2 (Condition: CPS vs. control) $\times 2$ (Test Day: forgetting on Day 2 vs. forgetting on Day 3) mixed factorial ANOVA did not result in any significant effects $\left(F_{\mathrm{S}}<1\right)$. For men, the same analysis revealed a significant effect of Condition, $F(1,35)=5.81, M S E=$ $.036, p=.021$, but no effect of test day, and no interaction between the two factors ( $F \mathrm{~s} \leq 1.97, p \geq .17$ ). Men forgot significantly less when they retrieved information after the CPS in comparison to the warm water condition $(M=.30, S D=.11$ for CPS, and $M=.13, S D=17$ for the warm water control).

\section{Discussion}

The present article tested whether stress affects retrieval and delayed recall of educationally relevant material. This question has important educational implications. While active retrieval has been shown to promote meaningful long-term learning (Karpicke, 2012), formalized tests in the classroom might have opposite effects, because test taking is experienced by many students as stress inducing and anxiety provoking. To test the effects of stress on retrieval, we subjected female and male participants to either cold pressor stress or a control condition, and asked them to recall a scientific text passage they had memorized on the previous day. Furthermore, to test the effects of retrieval under stress on delayed retention, we asked participants to recall the passage again $24 \mathrm{hr}$ later.

CPS caused significant increases in salivary cortisol in male participants, indicating a stress response. Based on previous research (Tollenaar et al., 2008a), we had predicted that stress would have immediate detrimental effects on retrieval. However, and in contrast to our prediction, we found that cold pressor stress (in comparison to a warm water control) enhanced retrieval performance in male participants. Most previous studies did not find effects of stress on retrieval of neutral material (e.g., Wolf et al., 2002; Domes et al., 2004). In these studies memory was assessed after a delay at a time when cortisol levels were still high, but noradrenergic activity had already declined. Our study is methodologically different in that we tested memory immediately after the stressor when noradrenergic activity was elevated, which has been discussed as one of the necessary preconditions of stress effects on retrieval (Roozendaal et al., 2004). However, Tollenaar et al. (2008a) also used an immediate test procedure but found impairing, as opposed to enhancing, effects of stress on retrieval. Several factors might account for these differences, including basal cortisol levels, type of stressor, and study material.

Participants in Tollenaar et al.'s study had slightly higher basal cortisol and stress-induced cortisol levels than participants in our and the two other studies that reported enhancing effects of stress/ cortisol on retrieval. Specifically, Schwabe et al. (2009) report positive effects of CPS on recall (of emotional words), and Lupien et al. (2002) found positive effects of hydrocortisone injections on 
retrieval when participants were tested in the afternoon. That a critical amount of cortisol is important for retrieval is further supported by a recent study showing that a reduction of endogenous high levels of cortisol in the morning by administrating the cortisol synthesis inhibitor metyrapone results in impaired recall of neutral and emotional text material (Rimmele, Meier, Lange, \& Born, 2010). It could be speculated that cortisol effects on retrieval follow the same inverted U-shape function that was originally proposed by Lupien and McEwen (1997) for encoding and consolidation processes (see Schwabe et al., 2009, and Rimmele et al., 2010 for similar arguments). Cognitive function, including retrieval, seems optimal when most of the MRs, but only some of the GRs are activated (increased MR/GR ratio), while cognitive processes suffer from low MR/GR ratios (e.g., deKloet, Oitzl, \& Joëls, 1999; Lupien et al., 2002). Hence, very low levels of cortisol (e.g., as accomplished by administering the cortisol synthesis inhibitor metyrapone in the morning, Rimmele et al., 2010), and very high levels of cortisol (e.g., as accomplished by administering hydrocortisone, see Het et al., 2005, for review, or by stressing people in the morning or midday, e.g., Kuhlman et al., 2005; Tollenaar et al., 2008) impair retrieval processes, while medium levels of cortisol might result in enhanced retrieval (Lupien et al., 2002; Schwabe et al., 2009; our study). Other studies, however, do not support the idea of an inverted U-shape function. Buchanan and Tranel (2008) report impaired recall of narrated photographs in participants who responded to a psychological stressor with cortisol increases, but enhanced memory in stressed participants who did not show a cortisol increase. Because of methodological differences, crossstudy comparisons are always difficult to interpret, and future dose-dependent studies are needed to test the hypothesis that the effects of cortisol on retrieval follow an inverted a U-shaped function.

Despite the differences in stress-induced cortisol levels that could determine the direction of stress effects on retrieval, the nature of the stressor is also likely to affect cognitive processes differently. Tollenaar et al. (2008a) used a psychological stressor (TSST) while the current study used a physiological stressor (CPS). It seems reasonable to assume that public speaking in front of an audience, as requested from participants in TSST, is accompanied by feelings of embarrassment and perceived threat to self image, which might cause lingering rumination and distraction even after the TSST is over. Those psychological aftereffects might contribute to the retrieval impairments observed in Tollenaar et al.'s study. In contrast, the physiological stressor used in our study is unlikely to cause such psychological effects, and thus allows for retrieval enhancement.

Another methodological difference between our and previous studies is the type of study material. While most studies used lists of words or pictures (but see Merz et al., 2010), we presented subjects with a passage of a scientific text. The individual facts presented therein were highly interconnected, and therefore it can be assumed that they mutually promoted their retrieval: If stress affects retrieval because it somehow distracts or decreases available retrieval resources, then anything that promotes retrieval might counteract this effect, allowing for overall net positive effects of stress on retrieval. In addition, it is likely that our material was more interesting and engaging to students, which might also modulate the stress effects on memory.
The memory enhancement for men was not only seen in the recall test that immediately followed the stressor, but also in the 48 hr-delayed test. This shows that moderate stress does not only have immediate effects on retrieval, but can improve retention after a delay. Memory performance on Day 3 was not different from performance on Day 2, which replicates Tollenaar et al. (2009), but stands in contrast to an earlier study by the same group (Tollenaar et al., 2008b) which found further decline in one group (that was tested first 5 weeks after encoding, and again 6 months later) and slight enhancement in another group (that was tested first 1 day after encoding, and again 6 months later). According to Tollenaar et al. (2008b), this reflects that stress did not only affect the retrieval process itself, but also postretrieval reconsolidation processes (Coccoz et al., 2012; Schwabe \& Wolf, 2010). In our study it is difficult to disentangle these two effects. The fact that stress did not further enhance memory on Day 3 suggests that stress did not specifically affect the reconsolidation process but caused prolonged benefits through enhancement of the testing effect on Day 2 (i.e., meaningful rehearsal, reencoding, establishing additional retrieval routes).

One caveat of our study is that CPS did not affect memory retrieval in women. This replicates previous findings of smaller stress effects in women compared with men (e.g., Buchanan \& Tranel, 2008; Schoofs \& Wolf, 2009). In fact, women showed only marginally elevated cortisol levels in response to the CPS, which is most likely because of oral contraceptive use which was highly prevalent in our female sample (e.g., Kirschbaum et al., 1999).

To our knowledge, the present study is the first to show beneficial effects of moderate stress on immediate and delayed retrieval: stress can optimize performance in a testing situation with longer lasting positive consequences for the memory that is retrieved. Future studies need to carefully evaluate the proposed inverted U-shape relationship between cortisol levels and retrieval, take a closer look at the effects of different stressors on retrieval, differentiate between cortisol-related and psychologically mediated effects of stress on cognitive processes, and test how the specifics of the to-be-remembered material might modulate stress effects on memory.

\section{References}

Buchanan, T. W., \& Tranel, D. (2008). Stress and emotional memory retrieval: Effects of sex and cortisol response. Neurobiology of Learning and Memory, 89, 134-141. doi:10.1016/j.nlm.2007.07.003

Cannon, W. B. (1929). Bodily changes in pain, hunger, fear, and rage. New York, NY: Appleton-Century-Crofts.

Chan, J. C. K., McDermott, K. B., \& Roediger, H. L. (2006). Retrievalinduced facilitation: Initially nontested material can benefit from prior testing of related material. Journal of Experimental Psychology: General, 135, 533-571.

Charmandari, E., Tsigos, C., \& Chrousos, G. (2005). Endocrinology of the stress response. Annual Review of Physiology, 67, 259-284. doi: 10.1146/annurev.physiol.67.040403.120816

Coccoz, V., Maldonado, H., \& Delorenzi, A. (2011). The enhancement of reconsolidation with a naturalistic mild stressor improves the expression of a declarative memory in humans. Neuroscience, 185, 61-72. doi: 10.1016/j.neuroscience.2011.04.023

de Kloet, E. R., Oitzl, M. S., \& Joels, M. (1999). Stress and cognition: Are corticosteroids good guys or bad guys? Trends in Neurosciences, 22, 422-426. doi:10.1016/S0166-2236(99)01438-1 
Domes, G., Heinrichs, M., Rimmele, U., Reichwald, U., \& Hautzinger, M. (2004). Acute stress impairs recognition for positive words: Association with stress-induced cortisol secretion. Stress: The International Journal on the Biology of Stress, 7, 173-181. doi:10.1080/10253890412331273213

Duncko, R., Johnson, L., Merikangas, K., \& Grillon, C. (2009). Working memory performance after acute exposure to the cold pressor stress in healthy volunteers. Neurobiology of Learning and Memory, 91, 377381. doi:10.1016/j.nlm.2009.01.006

Groeneweg, F. L., Karst, H., de Kloet, E. R., \& Joels, M. (2011). Rapid non-genomic effects of corticosteroids and their role in the central stress response. Journal of Endocrinology, 209, 153-167.

Het, S., Ramlow, G., \& Wolf, O. T. (2005). A meta-analytic review of the effects of acute cortisol administration on human memory. Psychoneuroendocrinology, 30, 771-784. doi:10.1016/j.psyneuen.2005.03.005

Karpicke, J. D. (2012). Retrieval-based learning: Active retrieval promotes meaningful learning. Current Directions in Psychological Science, 21, 157-163. doi:10.1177/0963721412443552

Kirschbaum, C., Wolf, O. T., May, M., Wippich, W., \& Hellhammer, D. H. (1996). Stress- and treatment-induced elevation of free cortisol levels associated with impaired declarative memory in healthy adults. Life Sciences, 58, 1475-1483. doi:10.1016/0024-3205(96)00118-X

Kuhlmann, S., Piel, M., \& Wolf, O. T. (2005). Impaired memory retrieval after psychosocial stress in healthy young men. Journal of Neuroscience, 25, 2977-2982. doi:10.1523/JNEUROSCI.5139-04.2005

Lovallo, W. (1975). The Cold Pressor Test and autonomic function: A review and integration. Psychophysiology, 12, 268-282. doi:10.1111/j .1469-8986.1975.tb01289.x

Lupien, S., \& McEwen, B. S. (1997). The acute effects of corticosteroids on cognition: Integration of animal and human model studies. Brain Research Reviews, 24, 1-27. doi:10.1016/S0165-0173(97)00004-0

Lupien, S. J., Wilkinson, C. W., Briere, S., Menard, C., Ng Ying Kin, N. M., \& Nair, N. P. (2002). The modulatory effects of corticosteroids on cognition: Studies in young human populations. Psychoneuroendocrinology, 27, 401-416. doi:10.1016/S0306-4530(01)00061-0

Maheu, F. S., Collicutt, P., Kornik, R., Moszkowski, R., \& Lupien, S. J. (2005). The perfect time to be stressed: A differential modulation of human memory by stress applied in the morning or in the afternoon. Progress in Neuro-Psychopharmacological \& Biological Psychiatry, 29, 1281-1288. doi:10.1016/j.pnpbp.2005.08.012

McDaniel, M. A., Anderson, J. L., Derbish, M. H., \& Morrisette, N. (2007). Testing the testing effect in the classroom. European Journal of Cognitive Psychology, 19, 494-513. doi:10.1080/09541440701326154

McDaniel, M. A., Roediger, H. L., \& McDermott, K. B. (2007). Generalizing test-enhanced learning from the laboratory to the classroom. Psychonomic Bulletin \& Review, 14, 200-206. doi:10.3758/BF03194052

Merz, C. J., Wolf, O. T., \& Hennig, J. (2010). Stress impairs retrieval of socially relevant information. Behavioral Neuroscience, 2, 288-293. doi:10.1037/a0018942

Porcelli, A. J., \& Delgado, M. R. (2009). Acute stress modulates risktaking in financial decision-making. Psychological Science, 20, 278283. doi:10.1111/j.1467-9280.2009.02288.x

Reul, J. M., \& De Kloet, E. R. (1985). Two receptor systems for corticosterone in rat brain: Microdistribution and differential occupation. Endocrinology, 117, 2505-2511. doi:10.1210/endo-117-6-2505

Rimmele, U., Meier, F., Lange, T., \& Born, J. (2010). Suppressing the morning rise in cortisol impairs free recall. Learning \& Memory, 17, 186-190. doi:10.1101/lm.1728510

Roediger, H. L., III, \& Karpicke, J. D. (2006). Test-enhanced learning: Taking memory tests improves long-term retention. Psychological Science, 17, 249-255. doi:10.1111/j.1467-9280.2006.01693.x

Rogers, B. (2001). TOEFL CBT Success. Princeton, NJ: Peterson's. Roozendaal, B. (2002). Stress and memory: Opposing effects of glucocorticoids on memory consolidation and memory retrieval. Neurobiology of Learning and Memory, 78, 578-595. doi:10.1006/nlme.2002.4080
Roozendaal, B., Hahn, E. L., Nathan, S. V., deq Uervain, D. J., \& McGaugh, J. L. (2004). Glucocorticoid effects on memory retrieval require concurrent noradrenergic activity in the hippocampus and basolateral amygdala. The Journal of Neuroscience, 24, 8161-8169. doi: 10.1523/JNEUROSCI.2574-04.2004

Roozendaal, B., \& McGaugh, J. L. (2011). Memory modulation. Behavioral Neuroscience, 125, 797-824. doi:10.1037/a0026187

Schoofs, D., Wolf, O. T., \& Smeets, T. (2009). Cold pressor stress impairs performance on working memory tasks requiring executive functions in healthy young men. Behavioral Neuroscience, 123, 1066-1075. doi: 10.1037/a0016980

Schwabe, L., Haddad, L., \& Schächinger, H. (2008). HPA axis activation by a socially evaluated cold pressor test. Psychoneuroendocrinology, 33, 890-895. doi:10.1016/j.psyneuen.2008.03.001

Schwabe, L., Joëls, M., Roozendaal, B., Wolf, O. T., \& Oitzl, M. S. (2012). Stress effects on memory: An update and integration. Neuroscience \& Biobehavioral Reviews.

Schwabe, L., Römer, S., Richter, S., Dockendorf, S., Bilak, B., \& Schächtinger, H. (2009). Stress effects on declarative memory retrieval are blocked by $\beta$-andrenoceptor anatagonist in humans. Psychoneuroendocrinology, 34, 446-454. doi:10.1016/j.psyneuen.2008.10.009

Schwabe, L., \& Wolf, O. T. (2010). Stress impairs the reconsolidation of autobiographical memories. Neurobiology of Learning and Memory, 94, 153-157. doi:10.1016/j.nlm.2010.05.001

Segal, S., \& Cahill, L. (2009). Endogenous noradrenergic activation and subsequent memory in men and women. Psychoneuroendocrinology, 34, $1263-1271$.

Smeets, T., Otgaar, H., Candel, I., \& Wolf, O. T. (2008). True or false? Memory is differentially affected by stress-induced cortisol elevations and sympathetic activity at consolidation and retrieval. Psychoneuroendocrinology, 33, 1378-1386. doi:10.1016/j.psyneuen.2008.07.009

Taverniers, J., Taylor, M. K., \& Smeets, T. (in press). Delayed memory effects after intense stress in Special Forces candidates: Exploring path processes between cortisol secretion and memory recall. Stress: The International Journal on the Biology of Stress.

Tollenaar, M. S., Elzinga, B., Spinhoven, P., \& Everaerd, W. T. A. M. (2008a). The effects of cortisol increase on long-term memory retrieval during and after acute psychosocial stress. Acta Psychologica, 127, 542-552. doi:10.1016/j.actpsy.2007.10.007

Tollenaar, M. S., Elzinga, B., Spinhoven, P., \& Everaerd, W. T. A. M. (2008b). Long-term outcomes of memory retrieval under stress (2008). Behavioral Neuroscience, 122, 697-703. doi:10.1037/0735-7044.122.3 .697

Tollenaar, M. S., Elzinga, B., Spinhoven, P., \& Everaerd, W. T. A. M (2009). Psychophysiologic responding to emotional memories in healthy young men after cortisol and propranolol administration. Psychophar macology, 203, 793-803. doi:10.1007/s00213-008-1427-x

Wheeler, M. A., Ewers, M., \& Buonanno, J. F. (2003). Different rates of forgetting following study versus test trials. Memory, 11, 571-580.

Wolf, O. T. (2009). Stress and memory in humans: Twelve years of progress? Brain Research, 1293, 142-154. doi:10.1016/j.brainres.2009 .04 .013

Wolf, O. T., Schommer, N., Hellhammer, D. H., Reischies, F. M., \& Kirschbaum, C. (2002). Moderate psychosocial stress appears not to impair recall of words learned four weeks prior to stress exposure Stress: The International Journal on the Biology of Stress, 5, 59-64. doi:10.1080/102538902900012332

Received August 2, 2012

Revision received September 12, 2012 Accepted September 15, 2012 